International Journal of Instruction e-ISSN: 1308-1470 • www.e-iji.net

Article submission code: 20201228175236

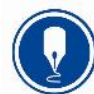

January $2022 \bullet$ Vol.15, No.1

p-ISSN: 1694-609X

pp. 457-472

Received: 28/12/2020

Revision: 07/07/2021
Accepted: 31/07/2021

OnlineFirst: 29/10/2021

\title{
Research on Students in COVID-19 Pandemic Outbreaks: A Bibliometric Network Analysis
}

\section{Chinun Boonroungrut}

Dr., Department of Psychology and Guidance, Faculty of Education, Silpakorn University, Thailand, boonroungrut_c@silpakorn.edu

\section{Wulan Patria Saroinsong}

Corresponding author, Dr., Department of Childhood Education, Faculty of Education, Universitas Negri Surabaya, Indonesia, wulansaroinsong @unesa.ac.id

\section{Natthaya Thamdee}

Department of General Education, Faculty of Education, Vongchavalitkul University, Thailand,nuttaya87@gmail.com

Over a billion students worldwide have suffered from school closure since the beginning of COVID-19 due to confinement. Educational Researchers have been illustrating various issues in the form of thousands of publications which signifies a significant academic interest. This review aimed to portray the vast scientific landscape of COVID-19 and students' experience in the current research directions. As many as 2,055 Scopus-indexed articles released between 2020 and 2021 (online publications) were retrieved by PRIMA guideline to be reviewed. We performed Bibliometric network analysis using VOSviewer software to generate the articles authors' keywords mapping, temporal authors' keywords mapping, and country collaboration mapping. Researchers from the U.S., China and the U.K. led the overall published articles. Furthermore, the researchers found nine publications related to student mental health and medical education, which indicate a new trend. On the other hand, Latin American and African countries are the most unproductive in this field. This article presents a complementary educational approach to understanding a comprehensive picture of what researchers worldwide have been doing. Researchers suggest further future reviews of medical \& nursing education, distance learning, and social media use in times of a pandemic.

Keywords: student, COVID-19, bibliometric, network analysis, review

\section{INTRODUCTION}

The world has been facing a new disease called Coronavirus Disease 2019 (COVID-19). COVID-19 has spread to over 200 countries, with 68 million confirmed cases and has become a global pandemic. Over 3 billion people have been confined as a result of these

Citation: Boonroungrut, C., Thamdee, N., \& Saroinsong, W. P. (2022). Research on students in COVID-19 pandemic outbreaks: A bibliometric network analysis. International Journal of Instruction, 15(1), 457-472. https://doi.org/10.29333/iji.2022.15126a 
circumstances. Approximately 1.5 billion students have been affected by this situation due to school closure (Setiawan, 2020). As an effort to seek a deeper understanding of the situation, more than 15 thousand articles have been published by researchers all over the world exploring pathology, antiviral treatments and human experiences, including students from all education levels, medical \& nursing students, international students, and students with disabilities (Cao et al., 2020; Pragholapati, 2020; Qiu et al., 2020; Swift et al., 2020; Xiong et al., 2020; Aljaraideh, 2019).

There are positive and negative aspects in education during this healthcare disruption. Fatigue among all involvement in online learning and teaching is rapidly growing. Some educators declared the new pedagogical techniques using synchronous online tools for not only students but also learners in various fields; however, resilience and exertions between students and teachers have been consistently absent (Lee et al., 2021). During the pandemic outbreak, several countries have developed a way of motivating their students at home using online technology including MOOC as a learning platform. This is how the pandemic reshapes the education services thru accelerating digital education transformation. The increasing rate of MOOC users during the pandemic can represent the rapid digital expansion in education service. It could be a key for engaging people as an alternative method in this context with normal education and primary healthcare for people (Kang, 2021; Pandey et al., 2021).

Students receive experiences from E-learning that schools and universities apply for facilitating learning during the closure. While trying to adapt those changes, some students require to be supported physically and mentally. Several evidences indicated that students who had fixed mindset, age differences, and self-control trended to be difficult to adjust themselves to a new learning environment. Students in the period have more freedom to participate in learning, requiring limited and changed evaluation (Basilaia \& Kvavadze, 2020; Pokhrel \& Chhetri, 2021).

Unfortunately, education systems had to continue after school closures in coping with the infection. Students and educators felt the unexpected ripple effect of the pandemic. Students' undergone psychological and emotional distress in many communities around the world becomes researchers' interest because their findings declared some significant differences. For example, international students showed no interest in study abroad after the pandemic, concerning social and economic inequalities across different educational systems (Mok et al., 2021). The economy after the pandemic had serious consequences for many students (Van de Velde et al., 2021). Additionally, students reported more moody, perceived stress and alcohol use than before the pandemic. Generally, white students reported greater effect from psychological distress than other students, and younger seemed to be less serious than older adults (Charles, 2021).

Although many researchers have reviewed COVID-19 related to several aspects of education by adopting a common review method to collect data on specific topics from different times and sources, a comprehensive view of all research has never been presented. It should be noted that the number of published comprehensive reviews are far less than the 16,000 COVID-19 related papers in all database (Yu et al., 2020). Thus, a bibliometric analysis was applied using a quantitative statistical technique based 
on the target research papers on the relevant topics via visualized network mapping (Moed, 2012). This review method analyzes the key terms from the publication titles, abstracts, and keywords, and predicts the trend of past-to-present studies.

The completeness of new transformative knowledge can be obtained fully from these academic publications. Therefore, this review is appropriate to visualize the broad landscape of COVID-19 and students from what researchers have done from 2020 to 2021. Hence, the purpose of this paper is to provide a bibliometric overview of research clusters and directions from productive countries regarding the topics between COVID19 and students.

\section{METHOD}

\section{Article Samples}

The research articles in the Scopus database were target because the database is one of the biggest abstract indexed databases (Hamidah, Sriyono \& Hudha, 2020). There were 2,591 records consisted of the words 'COVID-19' and 'Student'. We used the Boolean search technique. At least one of those keywords must be explicitly stated in their titles, abstracts or keywords. The samples were articles published between 2020 (indexed up to December 5, 2020) and 2021 for online release and in press articles. The selected samples were 2,055 articles which excluded 235 incorporate articles, 153 conference papers and 121 reviews. Furthermore, the samples were articles published by 2,886 authors and co-authors and cited by 3,694 other documents. PRIMA guideline was also adopted to identify the article samples in this study, as shown in Figure 1 (Moher, Liberati, Tetzlaff, Altman, \& Group, 2010).

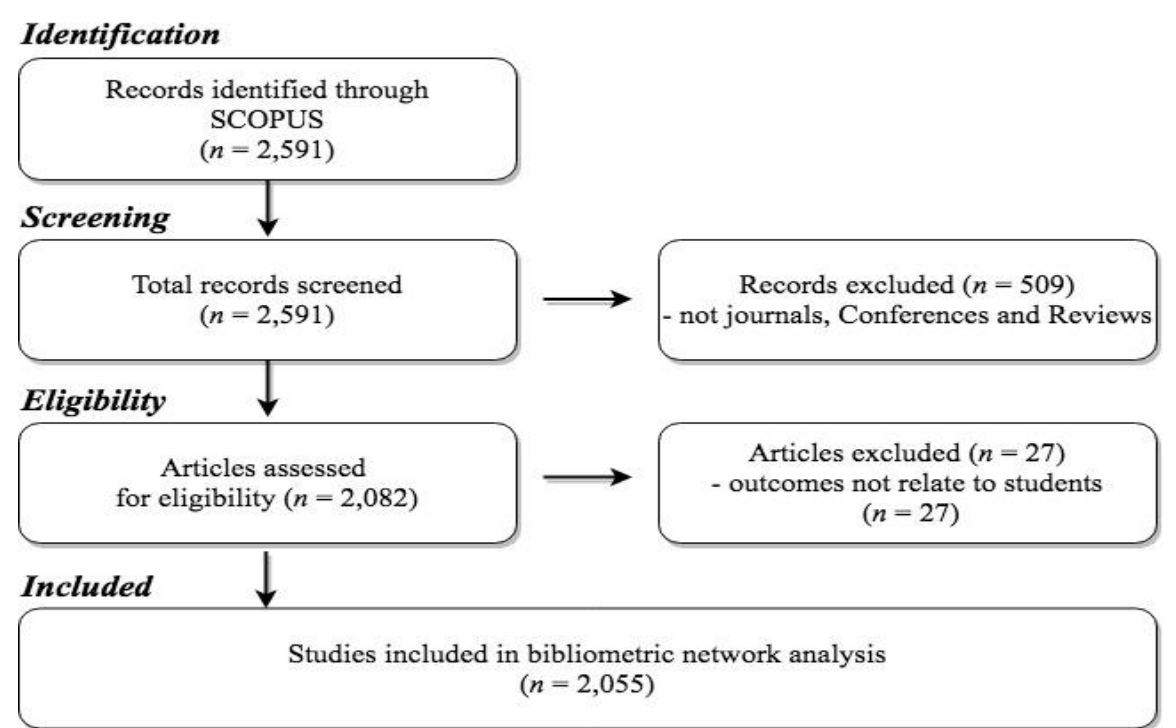

Figure 1

PRISMA flow for sample identification 
These samples were included in the top three journals that gained the most interest from worldwide researchers. The most productive journals in this field were Journal of Chemical Education (6.90\% of all samples), followed by International Journal of Environmental Research and Public Health $(2.48 \%)$ and Sustainability Switzerland $(1.50 \%)$. The most cited journal was in the International Journal of Environmental Research and Public Health (5.08\% of all cited articles). In terms of citations, only the Journal of Chemical Education did not appear as the top ten-ranked journal. The authors and co-authors from the United States (U.S.) (28.41\%), China (8.02\%), and United Kingdom $(6.76 \%)$ were the world's top three contributors. Furthermore, Harvard Medical School (U.S.), Saveetha Institute of Medical and Technical Sciences (India), University of Pennsylvania (U.S.), and Saveetha Dental College and Hospital (India) were the world-leading affiliation. However, the most cited published research was from the University of Toronto (Canada).

\section{Data Analysis}

The bibliographic network analysis was used to create a map of co-occurrences exploring the authors' research keywords. In terms of the network calculations, the authors' keywords were visualized without the key term 'COVID-19' and its related terms. This omission might provide a clearer cluster among explored authors' keywords. The mapping nodes and their relations were represented using different color spots and lines to link them as clusters. The size of a circle was calculated based on cooccurrences which referred to the searched articles and terms. First, a cluster network mapping was visualized together with temporal overlay visualization, which presented updated authors' key terms in this study - the colors of circles referred to each cluster and their membership. Second, a country and co-country mapping were created by the calculated number of documents, demonstrating how researchers collaborated with different institutions in different countries.

Notably, the ease of interpretation, which showed highly frequent units, could affect the bibliometric mapping's visualized layout. In the preliminary testing, various occurrence threshold selections were conducted to present the primary research trends' full visibility. Inconsistent mappings were discarded to avoid any possible arbitrariness. Fractional weight and Lin-Log modularity were applied to set each units' normalization. The map of authors' keywords was calculated from a minimum of 3 occurrences per term presenting 128 thresholds from 1,189 keywords. A co-country mapping included 117 countries that published more than 3 papers presenting 56 thresholds. The samples were analyzed by VOSviewer (version 1.16.13 on Mac OS) (Perianes-Rodriguez, Waltman, \& Van Eck, 2016).

\section{FINDINGS}

The authors' keywords co-occurrence mapping has visualized nine recognized clusters, as presented in Figure 2 and Table 1. The yellow cluster at the top left mostly includes the nodes on remote learning and emergency remote teaching, as well as medical and nursing students and quarantine. It was a trivial cluster compared to other clusters. The light blue cluster at the top center were nodes related to higher education and terms 
related to online behavior, Google Classroom and mobile application learning. The brown cluster next to the light blue cluster seemed to be related to terms from online learning approaches, including online learning and e-learning, and social distancing, such as health science and health crisis. The orange cluster next to the brown cluster included significant nodes related to distance learning and terms related to video conferencing tools, learning habits and social media. The red color cluster at the top consists of a significant node related to the curriculum as the betweenness-centric and terms related to self-instruction among various learners, such as upper-division undergraduate, second-year undergraduate graduate students. Besides, this cluster included several learning styles as tiny nodes such as collaborative learning, internet and web-based learning and multimedia-based learning.

This mapping presented the well-recognized cluster named the dark blue cluster. This cluster primarily includes the nodes on medical education and medical students' terms with measuring telehealth and social isolation variables. The most significant cluster in this mapping was the violet cluster at the bottom center position. This cluster contains nodes related to psychological factors, such as mental health, stress, depression and anxiety. Considerably, this cluster was closer to each other, which might represent how researchers gathered terms and used closely related approaches. The green cluster represents terms related to knowledge and perceptions, including attitudes and awareness among university students and dental students. The pink cluster was the narrowest cluster which contained the nodes about psychological factors on lockdown period including coping strategies, PTSD, well-being, social support and resilience. The light green cluster located at the bottom right includes terms related to international students in China and Australia. The last cluster, an old rose color located at the right side of the green color, contains the terms related to medical education and training linked with active learning and telemedicine. 


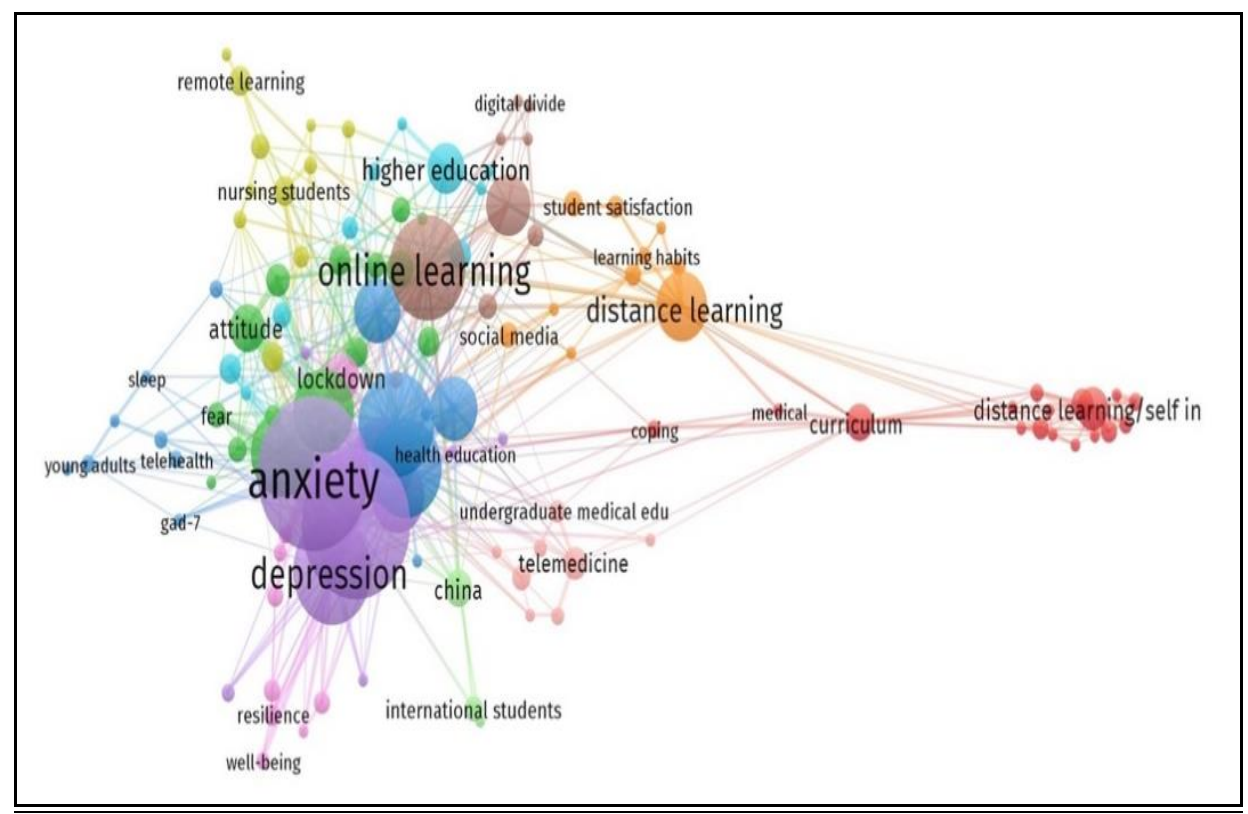

Figure 2

Authors' keywords co-occurrence Mapping

Table 1

Top 20 keywords' link strength

\begin{tabular}{llllllll}
\hline No & Keywords & Occurrences & $\begin{array}{l}\text { Link } \\
\text { Strength }\end{array}$ & No & Keywords & Occurrences & $\begin{array}{l}\text { Link } \\
\text { Strength }\end{array}$ \\
\hline 1 & Anxiety & 47 & 167 & 11 & Curriculum & 9 & 38 \\
\hline 2 & Mental Health & 45 & 146 & 12 & Lockdown & 12 & 38 \\
\hline 3 & Depression & 31 & 124 & 13 & Higher education & 13 & 35 \\
\hline 4 & Stress & 24 & 93 & 14 & Dental student & 9 & 25 \\
\hline 5 & Knowledge & 23 & 78 & 15 & Perception & 7 & 24 \\
\hline 6 & Medical students & 30 & 67 & 16 & Physical activity & 7 & 23 \\
\hline 7 & Online learning & 30 & 63 & 17 & China & 9 & 22 \\
\hline 8 & Distance learning & 19 & 62 & 18 & Coping & 5 & 22 \\
\hline 9 & Medical education & 28 & 56 & 19 & Quarantine & 7 & 22 \\
\hline 10 & Attitude & 12 & 43 & 20 & Fear & 6 & 21 \\
\hline
\end{tabular}

As presented in Figure 3, the latest terms were principally presented in the violet orange clusters and a small portion in the dark blue cluster compared to Figure 1. Emergency remote teaching is the newest term from the yellow cluster. The favored term of the brown cluster is distance learning. Another cluster consists of the latest terms, such as physical activity, exercise, and sleep, related to medical education. Topics on Mental health greatly interest worldwide researchers as the latest in the violet cluster. Lastly, research interest in students in China has been concluded as a current trend. 


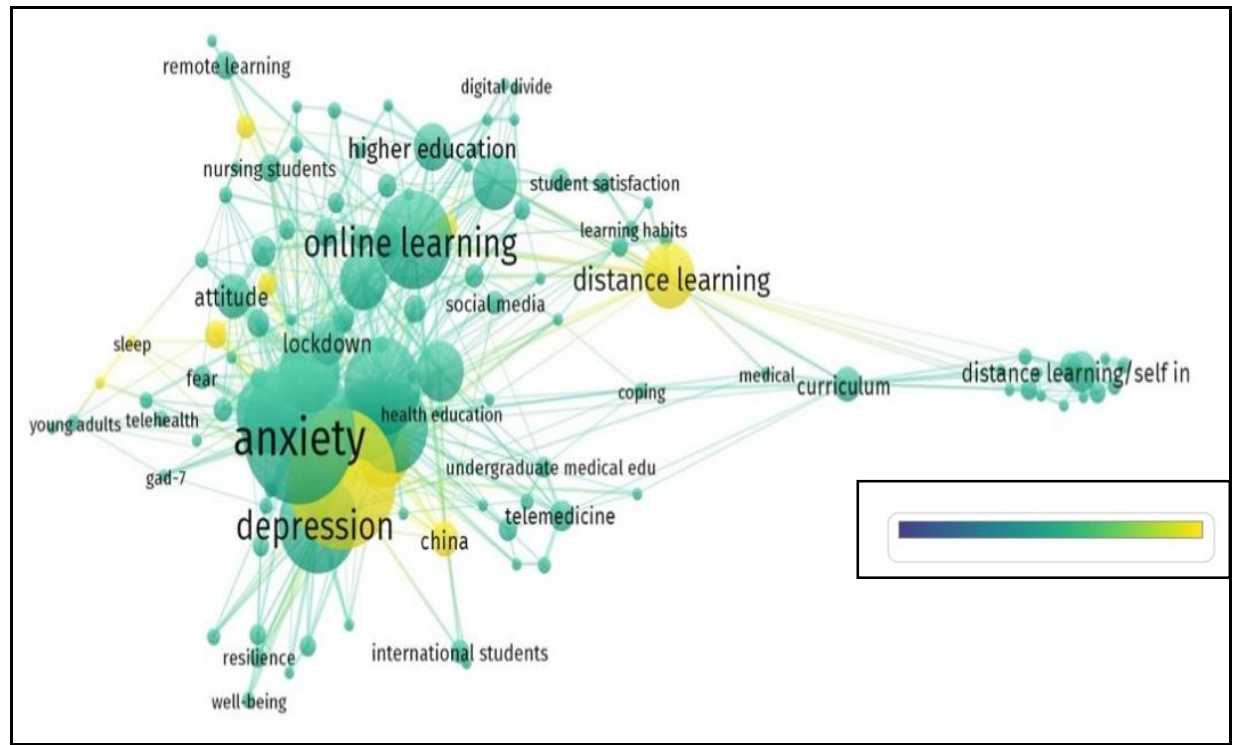

Figure 3

Authors' keywords co-occurrence Temporal Mapping

Note: Lighter color refers to update terms

A global overview of the leading countries mapping was contributed to academic publications related to student and COVID-19 within the pandemic outbreak, presented in Figure 4 and Table 2. The mapping presented 7 visualized clusters of various countries, including 5 major and 2 minor clusters. Counting without weighting population in any 117 countries in this study, researchers from the U.S., Spain, and Singapore, Italy and Vietnam, a red cluster, were clearly leading. Researchers from China had published more relevant articles with other East and South Asian countries, including India, Hong Kong and Thailand, a yellow cluster). As presented in the green cluster, Middle East countries, including Saudi Arabia, United Arab Emirates, and other South and Southeast Asian countries, Bangladesh, Pakistan, Malaysia, and Indonesia, tend to collaborate closely with one another. United Kingdom researchers, an orange cluster, worked closely with U.S. researchers. Remarkably, although the outbreak in Europe, Latin and African countries seemed to be serious, the overall productivity rates in this field were very low. 
Table 2

Most productive counties

\begin{tabular}{|c|c|c|c|c|c|c|}
\hline No & Countries & Ndoc & $\%$ Ndoc & NCitation & \%NCitation & Link Strength \\
\hline \multicolumn{7}{|c|}{ North America } \\
\hline 1 & United States & 175 & 16.55 & 562 & 29.30 & 40 \\
\hline 2 & Canada & 22 & 2.08 & 34 & 1.77 & 21 \\
\hline \multicolumn{7}{|c|}{ Asia \& Oceania } \\
\hline 1 & China & 73 & 7.37 & 509 & 26.53 & 20 \\
\hline 2 & Pakistan & 16 & 1.51 & 52 & 2.71 & 19 \\
\hline 3 & Saudi Arabia & 28 & 2.64 & 14 & .72 & 15 \\
\hline 4 & Australia & 30 & 2.83 & 30 & 1.56 & 12 \\
\hline 5 & Malaysia & 19 & 1.79 & 48 & 2.50 & 11 \\
\hline \multicolumn{7}{|c|}{ Europe } \\
\hline 1 & United Kingdom & 85 & 8.04 & 106 & 5.52 & 40 \\
\hline 2 & Italy & 13 & 1.22 & 23 & 1.19 & 11 \\
\hline 3 & Denmark & 5 & .47 & 31 & 1.61 & 10 \\
\hline 4 & Netherlands & 7 & .66 & 3 & .15 & 10 \\
\hline 5 & France & 11 & 1.04 & 8 & .41 & 8 \\
\hline \multicolumn{7}{|c|}{ Latin America } \\
\hline 1 & Peru & 7 & .66 & 2 & .10 & 5 \\
\hline 2 & Brazil & 13 & 1.22 & 9 & .46 & 1 \\
\hline 3 & Columbia & 7 & .66 & 2 & .10 & 1 \\
\hline 4 & Mexico & 5 & .47 & 2 & .10 & 0 \\
\hline
\end{tabular}

Note: The database recruited only 2 counties in North America and 4 countries in Latin.

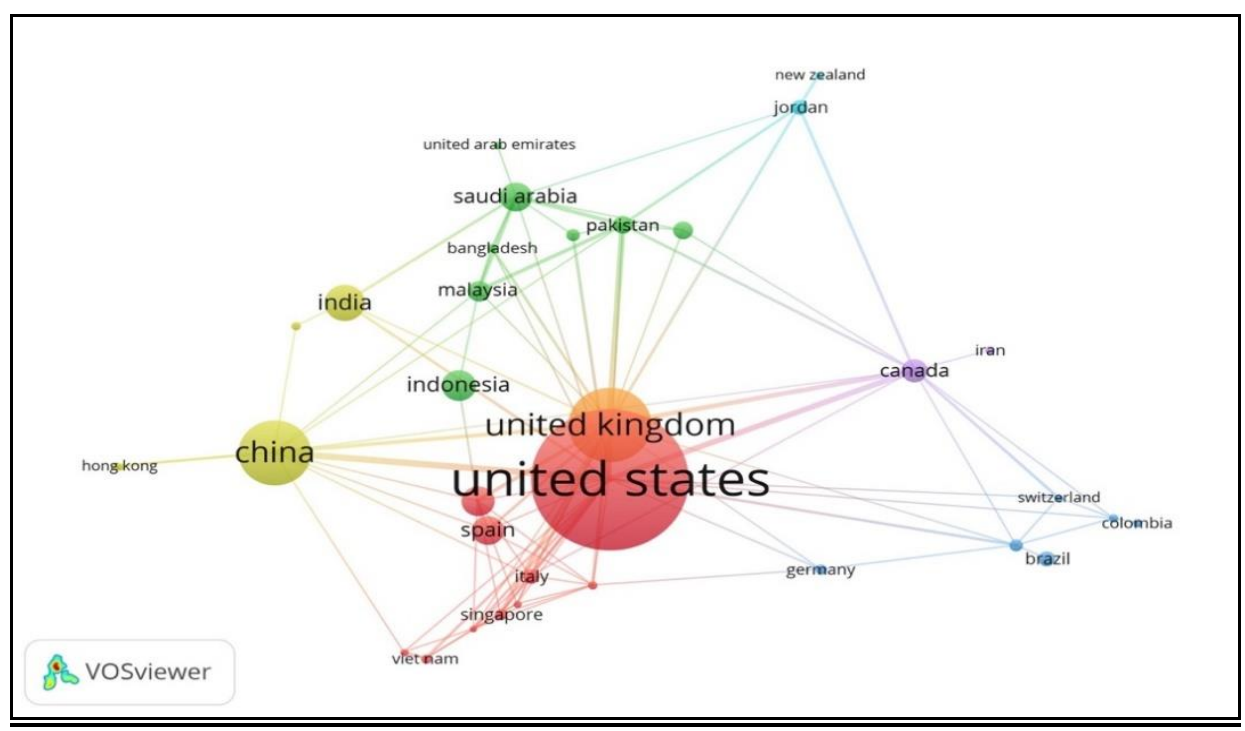

Figure 4

Co-country authorship

International Journal of Instruction, January $2022 \bullet$ Vol.15, No.1 


\section{DISCUSSION}

This review employed the bibliometric network analysis to overview researchers' studies worldwide on students during the COVID-19 pandemic. The samples were 2,055 Scopus-indexed articles. These samples were published by 2,886 authors and coauthors. It might be evidence of disseminating knowledge among researchers within this field. According to the main review findings, the following are the discussion sections that highlight several topics that could be reviewed in the future.

\section{COVID-19 and Students' Mental Health}

It was found that mental health was visualized as the most significant cluster, as presented in Figure 2 and 3. It signifies that most researchers showed interest in this issue, especially regarding depression and anxiety. Considerably, students were reported to present more psychiatric forms in this outbreak (Lei et al., 2020; Mazza et al., 2020; Wang et al., 2020). In a review of Xiong et al. (2020), students are at risk of developing more depressive symptoms than active and retired employees. Female students were higher than males. Moreover, Cao et al. (2020) and Qiu et al. (2020) indicated that when school closures happen, class cancellation examination postponements and remoting online courses, students tend to be more vulnerable to increasing emotional distress and PTSD symptoms.

Considering the influence of family protection factors, parental marital satisfaction, and intimacy trended to receive social support higher than family, which worsens parents' conflicts. In addition, families with university or college students exhibited fewer signs of depression and anxiety than other students' stages. The low economic class was more affected, with higher stress, depression and anxiety among parents who have sons or daughters in any learning stages (Husky, Kovess-Masfety, \& Swendsen, 2020; Patrick et al., 2020; Tang, Xiang, Cheung, \& Xiang, 2020; Wu et al., 2020). There were few subclinical misbehavior publications, such as eating and dietary restriction among students in lockdown period. It was confirmed that the higher the stress, the higher the risk of problematic eating behaviors, including eating habits and lifestyle changes (Bajramovic et al., 2020; Duong et al., 2020; Flaudias et al., 2020). Notably, student suicide cases related to learning issues were reported in some Asian counties (Lathabhavan \& Griffiths, 2020; Mamun, Chandrima, \& Griffiths, 2020; Ueda, Nordström, \& Matsubayashi, 2020; Utomo, Hasanah, Hariyadi \& Narulita, 2020).

This is an opportunity for school administrators to leverage mental care and resilience promoting factors to support students, including international students and dormitories, when returning to school are eventually suggested by almost researchers. The requirement to develop intervention or any service strategies to detect underlying mental health of student is imminent and professional support warrant a more effective approach to any possible future health disruption (King, Cabarkapa, Leow, \& Ng, 2020; Liu, Pinder-Amaker, Hahm, \& Chen, 2020; Son, Hegde, Smith, Wang, \& Sasangohar, 2020). 


\section{COVID-19 and Medical Student Education}

Medical student education in the outbreak gained tremendous interest. The advancement of telehealth and other protocols was flexibly approached and evaluated as a solution (Rose, 2020). Medical researches and innovative solutions were turning to face this public health problem in a huge variety of ways (Kinder \& Harvey, 2020; Miller, Pierson, \& Doernberg, 2020). Medical students volunteering as interprofessional practices, including health services and K-12 healthcare education engaging were reported in many settings as problem-based learning. The public projects might not occur when they did not hold typical opportunities (Buckland, 2020; Reardon et al., 2020). There was a significant effect on students' confidence and preparedness that assisting in some healthcare area during the outbreak could be a valuable learning experience (Choi et al., 2020). Medical education receives the advantage of e-learning in both students and teachers to develop new teaching strategies. Combining into useful blend learning modes can be successfully migrated to various medical education fields, including radiology, neurosurgery and oncology (Chae et al., 2020; Darras et al., 2020; Pollom et al., 2020).

\section{COVID-19 and Latino and African research}

According to the global overview mapping, Latin and African countries were insufficient in the sample to analyze. It referred to a small number of published publications and no systematic review, by researchers in those regions. One research was declared the interconnected dimensions, which indicated low social-economic students suffered from these consequent outcomes. Only one-third of students can access qualified online learning platforms. Several teachers faced issues with integrating digital devices into the curricula. It was found that almost half of the students could assess the internet connection at home. In addition, lack of parental support significantly affected students when they stayed at home because of their school closures (Alexander, Entwisle, \& Olson, 2001; Basto-Aguirre, Cerutti, \& Nieto-Parra, 2020). For the better discussion, some local indexed publications indicated that students in those Latin countries might face psychological distress the same as other areas in the world that might be further reviewed by local researchers. Students in these countries changed their dietary habits in this COVID-19 confinement by increasing food intake (Ruiz-Roso et al., 2020), and declared higher suicide risk (Caballero-Domínguez, Jiménez- Villamizar, \& Campo-Arias, 2020). Some researches among African students defined higher depression in female student (Rakhmanov \& Dane, 2020). There was a requirement for adequate communication infrastructure in higher education to connect students with their institutions during the closure (Marinoni, Van’t Land, \& Jensen, 2020).

In many studies, researchers explore the advantages of supporting applications that communicate with students, students and parents. Social media was adopted together with those learning applications and platforms. Interest in the massive open online course (MOOC) reach the highest rate in many countries. Students' ICT-based skills were developed in this lockdown period. Many countries provide psychological assistance to avoid the feeling of isolation. During this confinement, educational 
policymakers should consider students' mental health and support to their families and teachers (Boonroungrut \& Saroinsong, 2020; Chang \& Yano, 2020; Saroinsong, Reza, Khotimuh, \& Boonroungrut, 2020).

\section{LIMITATIONS AND CONCLUSIONS}

More academic articles have been published during the pandemic. The sample articles in this study were particularly big enough to review that could help researchers obtain valuable information for understanding COVID-19 influences on students using the bibliometric network. Several considerations should be noted before implementing these findings. The samples were taken from only the Scopus database; thus, a review from other research databases can be made in the future. Additionally, this study only included articles published in English. Exploring articles in other languages might be an option for local researchers.

In conclusion, nine visualized clusters of research related to COVID-19 and students were found by co-occurrence in the Scopus database. Publications on mental health and psychological factors gained the most interest from worldwide researchers followed by medical education and online learning \& distance learning. The temporal mapping indicated distance learning, mental health and several times related to physical activities as updated research terms. Geographical mapping revealed that researchers from the U.S., China and the U.K. were the world-leading authors in terms of quantity. There was a limited number of publications from Latin and African countries in this database. Finally, we recommend that researchers research medical and nursing education, distance learning, or social media use during a pandemic in the future.

\section{DISCLOSURE STATEMENT}

No conflict of interest was reported by the authors.

\section{REFERENCES}

Alexander, K. L., Entwisle, D. R., \& Olson, L. S. (2001). Schools, achievement, and inequality: A Seasonal Perspective. Educational Evaluation and Policy Analysis, 23(2), 171-191. doi.org/10.3102/01623737023002171

Aljaraideh, Y. (2019). Massive Open Online Learning (MOOC) Benefits and Challenges: A Case Study in Jordanian Context. International Journal of Instruction, 12(4), 65-78. doi.org/10.29333/iji.2019.1245a

Bajramovic, I., Redzepagic, S., Bjelica, D., Krivokapic, D., Jeleskovic, E., \& Likic, S. (2020). Level of Active Lifestyle and Exercise Approach among Sports-Active Female Students of The University of Sarajevo during the Covid-19 Pandemic. Journal of Anthropology of Sport and Physical Education, 4(4), 33-36. doi.org/10.26773/jaspe.201006

Basilaia, G., \& Kvavadze, D. (2020). Transition to online education in schools during a SARS-CoV-2 coronavirus (COVID-19) pandemic in Georgia. Pedagogical Research, 5(4), 133-140. doi.org/10.29333/pr/7937 
Basto-Aguirre, N., Cerutti, P., \& Nieto-Parra, S. (2020). COVID-19 can widen educational gaps in Latin America: some lessons for urgent policy action. Retrieved fromhttp://www.lacea.org/vox/?q=blog/covid19_widen_educational_gaps

Boonroungrut, C., \& Saroinsong, W. P. (2020). Analysis of Public Interest in MOOCs Using Google Trends®: An Evidence from Thai Domestic and International MOOC Providers. (Unpublished Work).

Buckland, R. (2020). Medical student volunteering during COVID-19: lessons for future interprofessional practice. Journal of Interprofessional Care, 34(5), 679-681.

Caballero-Domínguez, C. C., Jiménez-Villamizar, M. P., \& Campo-Arias, A. (2020). Suicide risk during the lockdown due to coronavirus disease (COVID-19) in Colombia. Death studies, 1-6.

Cao, W., Fang, Z., Hou, G., Han, M., Xu, X., Dong, J., \& Zheng, J. (2020). The psychological impact of the COVID-19 epidemic on college students in China. Psychiatry research. 287, 1-5. doi.org/10.1016/j.psychres.2020.112934

Chae, J. K., Haghdel, A., Guadix, S. W., Winston, G. M., Younus, I., Radwanski, R., . . . Pannullo, S. C. (2020). COVID-19 impact on the medical student path to neurosurgery. Neurosurgery, 87(2). 232-233, doi.org/10.1093/neuros/ nyaa187

Chang, G.-C., \& Yano, S. (2020). How are countries addressing the Covid-19 challenges in education? A snapshot of policy measures. Retrieved from https://gemreportunesco.wordpress.com/2020/03/24/how-are-countries-addressing-thecovid-19-challenges-in-education-a-snapshot-of-policy-measures/

Charles, N. E., Strong, S. J., Burns, L. C., Bullerjahn, M. R., \& Serafine, K. M. (2021). Increased mood disorder symptoms, perceived stress, and alcohol use among college students during the COVID-19 pandemic. Psychiatry research, 296, 1-11.

Choi, B., Jegatheeswaran, L., Minocha, A., Alhilani, M., Nakhoul, M., \& Mutengesa, E. (2020). The impact of the COVID-19 pandemic on final year medical students in the United Kingdom: a national survey. BMC medical education, 20(1), 1-11. doi.org/10.1186/s12909-020-02117-1

Darras, K. E., Spouge, R. J., de Bruin, A. B., Sedlic, A., Hague, C., \& Forster, B. B. (2020). Undergraduate radiology education during the COVID-19 pandemic: a review of teaching and learning strategies. Canadian Association of Radiologists Journal, doi.org/10.1177/0846537120944821

Duong, T. V., Pham, K. M., Do, B. N., Kim, G. B., Dam, H. T., Le, V.-T. T., . . Le, T. T. (2020). Digital Healthy Diet Literacy and Self-Perceived Eating Behavior Change during COVID-19 Pandemic among Undergraduate Nursing and Medical Students: A Rapid Online Survey. International Journal of Environmental Research and Public Health, 17(19), 256-277 doi: 10.3390/ijerph17197185

Flaudias, V., Iceta, S., Zerhouni, O., Rodgers, R. F., Billieux, J., Llorca, P.-M., . . . Maurage, P. (2020). COVID-19 pandemic lockdown and problematic eating behaviors 
in a student population. Journal of Behavioral Addictions, 9(3), 826-835. doi.org/10.1556/2006.2020.00053

Hamidah, I., Sriyono, S., \& Hudha, M. N. (2020). A Bibliometric analysis of Covid-19 research using VOSviewer. Indonesian Journal of Science and Technology, 5(2), 209216. doi.org/10.17509/ijost.v5i2.24522

Husky, M. M., Kovess-Masfety, V., \& Swendsen, J. D. (2020). Stress and anxiety among university students in France during Covid-19 mandatory confinement. Comprehensive Psychiatry, 102, 1-3. doi.org/10.1016/j.comppsych. 2020.152191

Kang, B. (2021). How the COVID-19 pandemic is reshaping the education service. The Future of Service Post-COVID-19 Pandemic, 1, 15-36.

Kinder, F., \& Harvey, A. (2020). Covid-19: the medical students responding to the pandemic. BMJ Student, 369, 1-2 doi.org/10.1136/bmj.m2160

King, J. A., Cabarkapa, S., Leow, F. H., \& Ng, C. H. (2020). Addressing international student mental health during COVID-19: an imperative overdue. Australas Psychiatry, 28(4), 469-469. doi.org/10.1177/1039856220926934

Lee, K., Fanguy, M., Lu, X. S., \& Bligh, B. (2021). Student learning during COVID-19: It was not as bad as we feared. Distance Education, 42(1), 164-172.

Lathabhavan, R., \& Griffiths, M. (2020). First case of student suicide in India due to the COVID-19 education crisis: a brief report and preventive measures. Asian journal of psychiatry, 53. 1-3. doi.org/10.1016/j.ajp.2020.102202

Lei, L., Huang, X., Zhang, S., Yang, J., Yang, L., \& Xu, M. (2020). Comparison of prevalence and associated factors of anxiety and depression among people affected by versus people unaffected by quarantine during the COVID-19 epidemic in southwestern China. Medical Science Monitor: International Medical Journal of Experimental and Clinical Research, 26, 1-12. doi.org/10.12659/MSM.924609

Liu, C. H., Pinder-Amaker, S., Hahm, H. C., \& Chen, J. A. (2020). Priorities for addressing the impact of the COVID-19 pandemic on college student mental health. Journal of American College Health, 1-3. doi.org/10.1080/ 07448481.2020.1803882

Mamun, M. A., Chandrima, R. M., \& Griffiths, M. D. (2020). Mother and son suicide pact due to COVID-19-related online learning issues in Bangladesh: An unusual case report. International Journal of Mental Health and Addiction, 1-4. doi.org/10.1007/s11469-020-00362-5

Marinoni, G., Van't Land, H., \& Jensen, T. (2020). The impact of Covid-19 on higher education around the world. IAU Global Survey Report. Paris: France.

Mazza, C., Ricci, E., Biondi, S., Colasanti, M., Ferracuti, S., Napoli, C., \& Roma, P. (2020). A nationwide survey of psychological distress among italian people during the COVID-19 pandemic: Immediate psychological responses and associated factors. 
International Journal of Environmental Research and Public Health, 17(9), 1-14. doi.org/10.3390/ijerph17093165

Miller, D. G., Pierson, L., \& Doernberg, S. (2020). The role of medical students during the COVID-19 pandemic. In: American College of Physicians. Retrieved from https://www.acpjournals.org/doi/full/10.7326/M20-1281?url_ver=Z39.88-

2003\&rfr_id=ori:rid:crossref.org\&rfr_dat=cr_pub=pubmed

Moed, H. (2012). The use of big datasets in bibliometric research. Research Trends, 30, 31-33. doi.org/10.7326/M20-1281

Moher, D., Liberati, A., Tetzlaff, J., Altman, D. G., \& Group, P. (2010). Preferred reporting items for systematic reviews and meta-analyses: the PRISMA statement. International journal of surgery, 8(5), 336-341. doi.org/ 10.1016/j.ijsu.2010.02.007

Mok, K. H., Xiong, W., Ke, G., \& Cheung, J. O. W. (2021). Impact of COVID-19 pandemic on international higher education and student mobility: Student perspectives from mainland China and Hong Kong. International Journal of Educational Research, 105, 1-11.

Pandey, D., Ogunmola, G. A., Enbeyle, W., Abdullahi, M., Pandey, B. K., \& Pramanik, S. (2021). COVID-19: A framework for effective delivering of online classes during lockdown. Human Arenas, 1, 1-15.

Patrick, S. W., Henkhaus, L. E., Zickafoose, J. S., Lovell, K., Halvorson, A., Loch, S., . . . Davis, M. M. (2020). Well-being of parents and children during the COVID-19 pandemic: a national survey. Pediatrics, 146(4) 202-227. doi.org/10.1542/peds.20200836

Perianes-Rodriguez, A., Waltman, L., \& Van Eck, N. J. (2016). Constructing bibliometric networks: A comparison between full and fractional counting. Journal of Informetrics, 10(4), 1178-1195. doi.org/10.1016/j.joi.2016.10.006

Pokhrel, S., \& Chhetri, R. (2021). A Literature Review on Impact of COVID-19 Pandemic on Teaching and Learning. Higher Education for the Future, 8(1), 133-141.

Pollom, E. L., Sandhu, N., Frank, J., Miller, J. A., Obeid, J.-P., Kastelowitz, N., . . . Donaldson, S. S. (2020). Continuing medical student education during the coronavirus disease 2019 (COVID-19) pandemic: Development of a virtual radiation oncology clerkship. Advances in radiation oncology, 5(4), 732-736. doi.org/10.1016/j.adro.2020.05.006

Pragholapati, A. (2020). COVID-19 IMPACT ON STUDENTS. Department of Nursing, Faculty of Sport Education and Health, Universitas Pendidikan Indonesia. Retrieved from https://edarxiv.org/895ed/

Qiu, J., Shen, B., Zhao, M., Wang, Z., Xie, B., \& Xu, Y. (2020). A nationwide survey of psychological distress among Chinese people in the COVID-19 epidemic: implications and policy recommendations. General psychiatry, 33(2), 1-3. doi.org/10.1136/gpsych2020-100213 
Rakhmanov, O., \& Dane, S. (2020). Knowledge and anxiety levels of African university students against COVID-19 during the pandemic outbreak by an online survey. J Res Med Dental Sci, 8(3), 53-56.

Reardon, R., Beyer, L., Carpenter, K., Irwin, M., Kester, K., Laird, J., . . . Conrad, R. (2020). Medical Student Development of K-12 Educational Resources During the COVID-19 Pandemic. Academic Pediatrics, 20(6), 763-764. doi.org/ 10.1016/j.acap.2020.05.022

Rose, S. (2020). Medical student education in the time of COVID-19. JAMA Network, 323(21), 2131-2132. doi.org/ 10.1001/jama.2020.5227

Ruiz-Roso, M. B., de Carvalho Padilha, P., Mantilla-Escalante, D. C., Ulloa, N., Brun, P., Acevedo-Correa, D., . . . de Oliveira Cardoso, L. (2020). Covid-19 confinement and changes of adolescent's dietary trends in Italy, Spain, Chile, Colombia and Brazil. Nutrients, 12(6), 1807-1821. doi.org/10.3390/nu12061807

Saroinsong, W., Reza, M., Khotimuh, N., \& Boonroungrut, C. (2020). A Stress Immunity System of Covid-19 Through Academic Stress. Paper presented at the The International Joint Conference on Arts and Humanities (IJCAH 2020), Surabaya, Indonesia.

Setiawan, A. R. (2020). Scientific Literacy Worksheets for Distance Learning in the Topic of Coronavirus 2019 (COVID-19). (Unpublish Work). doi.org/ 10.35542/osf.io/swjmk

Son, C., Hegde, S., Smith, A., Wang, X., \& Sasangohar, F. (2020). Effects of COVID19 on college students' mental health in the United States: Interview survey study. Journal of medical internet research, 22(9), 1-14. doi.org/ 10.2196/21279

Swift, A., Banks, L., Baleswaran, A., Cooke, N., Little, C., McGrath, L., . . W Williams, G. (2020). COVID-19 and student nurses: A view from England. Journal of clinical nursing, 29, 17-18. doi: 10.1111/jocn.15298

Tang, S., Xiang, M., Cheung, T., \& Xiang, Y.-T. (2020). Mental health and its correlates among children and adolescents during COVID-19 school closure: The importance of parent-child discussion. Journal of Affective Disorders, 279. 353-360. https://doi.org/10.1016/j.jad.2020.10.016

Ueda, M., Nordström, R., \& Matsubayashi, T. (2020). Suicide and mental health during the COVID-19 pandemic in Japan. medRxiv. doi.org/10.1101/2020.10.06 .20207530

Utomo, A. P., Hasanah, L., Hariyadi, S., \& Narulita, E. (2020). The Effectiveness of STEAM-Based Biotechnology Module Equipped with Flash Animation for Biology Learning in High School. International Journal of Instruction, 13(2), 463-476. doi.org/10.29333/iji.2020.13232a

Van de Velde, S., Buffel, V., Bracke, P., Van Hal, G., Somogyi, N. M., Willems, B. (2021). The COVID-19 International Student Well-being Study. Scandinavian Journal of Public Health, 49(1), 114-122. 
Wang, C., Pan, R., Wan, X., Tan, Y., Xu, L., McIntyre, R. S., . . Sharma, V. K. (2020). A longitudinal study on the mental health of general population during the COVID-19 epidemic in China. Brain, Behavior, and Immunity, 87. 40-48. doi.org/ 10.1016/j.bbi.2020.04.028

Wu, M., Xu, W., Yao, Y., Zhang, L., Guo, L., Fan, J., \& Chen, J. (2020). Mental health status of students' parents during COVID-19 pandemic and its influence factors. General psychiatry, 33(4), 1-9. doi.org/10.1136/gpsych-2020-100250

Xiong, J., Lipsitz, O., Nasri, F., Lui, L. M., Gill, H., Phan, L., . . Majeed, A. (2020). Impact of COVID-19 pandemic on mental health in the general population: A systematic review. Journal of affective disorders, 277. 55-64. doi.org/ 10.1016/j.jad.2020.08.001

Yu, Y., Li, Y., Zhang, Z., Gu, Z., Zhong, H., Zha, Q., \& Yang, L. (2020). A bibliometric analysis using VOSviewer of publications on COVID-19. Annals of Translational Medicine, 8(13), 1-11. doi.org/10.21037/atm-20-4235 